\title{
The incompatibility loci as indicators of conserved linkage groups in the Poaceae
}

\author{
C. R. Leach and D. L. Hayman
}

Department of Genetics, University of Adelaide, Adelaide, South Australia 5000.

Linkage between an incompatibility locus and the locus of the gene encoding the enzyme glucose phosphoisomerase has been demonstrated for the grasses Alopecurus myosuroides, Phalaris coerulescens, Festuca pratensis, Holcus lanatus and Secale cereale suggesting the conservation of a common chromosomal element in the evolution of the Poaceae.

\section{INTRODUCTION}

Gametophytic self-incompatibility controlled by genes at two loci, first described by Lundqvist $(1954,1956)$ in Secale cereale and Hayman (1956) in Phalaris coerulescens has subsequently been found in all genetically analysed self-incompatible species belonging to the Poaceae (see Leach 1983 for references). This system is unique to the grasses and is presumed to have arisen only once. The two loci ( $S$ and $Z$ ) assort independently and each have a large number of different alleles, e.g., Festuca pratensis $S=14$ and $Z=13$ (Lundqvist, 1969). Identity between pollen and pistil for the alleles at each locus leads to incompatibility. Thus an $S_{1.2} Z_{1.2}$ style rejects all pollen of $S_{1} Z_{1}, S_{1} Z_{2}, S_{2} Z_{1}$, $S_{2} Z_{2}$ genotypes; specifically that produced by anthers of a plant of that genotype but will accept pollen differing by at least one $S$ or $Z$ allele.

$$
\begin{aligned}
& \text { e.g. } \quad \begin{array}{r}
S_{1.2} Z_{1.2} \times S_{1.3} Z_{1.2} \\
\downarrow
\end{array} \\
& S_{1} Z_{1} \quad S_{1} Z_{2} \quad S_{3} Z_{1} \quad S_{3} Z_{2}
\end{aligned}
$$

i.e. 50 per cent of pollen in such crosses would be compatible. Genotype combinations in which 75 per cent and 100 per cent of pollen is compatible are possible. A completely self-incompatible plant sets no seed with its own pollen and so crosses between plants of different incompatibility genotypes may be made by simply bagging heads together. The compatibility relationship between plants can be established from pollination tests.

As a result of the potential for differential transmission of different types of pollen, it follows that genes which are linked to the self-incompatibility genes may have a disturbed rate of transmission. Consider a pair of plants which are reciprocally 50 per cent incompatible and each of GPI-2 (glucose phosphoisomerase) type 1-3 with Gpi-2 linked to the $S$ locus. These could have genotypes

$$
\text { (f) } \frac{S_{2} P_{1}}{S_{3} P_{3}} Z_{1 \cdot 3} \times \text { (む) } \frac{S_{2} P_{1}}{S_{1} P_{3}} Z_{1 \cdot 3}
$$

(where $P_{1}$ is used to represent Gpi-2-1 etc.) and when crossed they would give the following gametes:

non-recombinant recombinant

$\begin{array}{ccc} & S_{2} P_{1} Z_{1} & S_{2} P_{3} Z_{1} \\ & S_{3} P_{3} Z_{1} & S_{3} P_{1} Z_{1} \\ & S_{2} P_{1} Z_{3} & S_{2} P_{3} Z_{3} \\ & S_{3} P_{3} Z_{3} & S_{3} P_{1} Z_{3} \\ \text { freq. of each } & \frac{1-r}{4} & \frac{r}{4} \\ & \text { non-recombinant } & \text { recombinant } \\ & \frac{S_{2} P_{1} Z_{1}}{S_{1} P_{3} Z_{1}} & \frac{S_{2} P_{3} Z_{1}}{S_{1} P_{1} Z_{1} *} \\ & \frac{S_{2} P_{1} Z_{3}}{S_{1} P_{3} Z_{3}} & S_{2} P_{3} Z_{3} \\ \text { freq. of each } & \frac{S_{1} P_{1} Z_{3} *}{4} & \frac{r}{4}\end{array}$

where $r=$ recombination frequency between the $S$ locus and Gpi-2 (P) locus. 
All pollen types $S_{2} Z_{1}$ and $S_{2} Z_{3}$ (circled) are incompatible and so Gpi-2-1 is transmitted only in recombinant gametes $S_{1} P_{1} Z_{1}$ and $S_{1} P_{1} Z_{3}(*)$. The female gametes carry Gpi-2-1 and Gpi-2-3 (indicated as $P_{1}$ and $P_{3}$ ) equally frequently leading to an expected proportion of $r / 2$ GPI type 1-1 in the progeny of this cross. GPI types 1-3 anci 3-3 have expectations of $\frac{1}{2}$ and $(1-r) / 2$ respectively. Other sorts of crosses may also lead to disturbed segregations but this cross is one from which the recombination fraction may be calculated using maximum likelihood estimation. Loci not linked to the incompatibility loci will not give disturbed segregation ratios.

\section{ANALYSIS}

The grasses are classified into 23 tribes, have a basic chromosome number of $n=5$ or $n=7$ and fossil records of grass pollen are found in the Paleocene (65 million years) (Muller, 1981). The chromosomes of species with a basic number of 7 are generally metacentric and form on average one chiasma per arm at metaphase. Very few plants are well mapped genetically; and gene mapping techniques are restricted since it is not possible to $\mathrm{G}$ band plant chromosomes in the same way as animal chromosomes or to set up somatic cell lines. However, the behaviour of the incompatibility system means that the linkage groups in which the incompatibility genes are located may be readily identified.

Linkage of PGI-2 (Gpi-2) (E.5.1.3.9) to one of the loci determining gametophytic self-incompatibility has been reported in Lolium perenne (Cornish et al., 1980) and in the closely related Lolium multiflorum (Fearon et al., 1983). These observations suggest the question "Is there evidence for the conservation of this linkage in other grasses with the same incompatibility system?"

Five species of grasses were chosen for study (table 1). The two locus incompatibility system has been demonstrated in three of these, Secale cereale (loc. cit.), Phalaris coerulescens (loc. cit.) and Festuca pratensis (Lundqvist, 1955; 1961). Holcus lanatus is highly self-incompatible, shows gametophytic determination of incompatibility and differences in the compatibility status between reciprocal crosses (Weimark, 1968). Alopecurus myosuroides is highly self-incompatible and shows gametophytic determination of incompatibility (Leach, unpublished). Both of these species are likely to have the same incompatibility system as is found in all other grasses. All species chosen were diploid with $n=7$ (Darlington et al., 1955) and each comes from taxonomically different tribes well separated on an evolutionary time scale (Stebbins, 1971).

With the exception of $S$. cereale all the species are perennials and so the procedure generally adopted to acquire plants of suitable incompatibility relationships has been to backcross progeny plants to parents. Where the original acquisitions were known to be sibs or half sibs pollination tests were carried out to establish pairs of plants suitable for crossing. $S$. cereale is an annual and so only sib crosses are possible. Many of the introductions of this species tested exhibited a degree of selfcompatibility and so an independent marker had to be used as an indicator of crossing. Table 1 shows the results of the linkage analyses carried out.

Table 1 Estimates of the recombination frequency between the $S$ locus and $G p i-2$ locus

\begin{tabular}{lllr}
\hline Species & $\begin{array}{l}\text { Recombination } \\
\text { frequency }\end{array}$ & $\begin{array}{l}\text { Standard } \\
\text { error }\end{array}$ & $\begin{array}{l}\text { Sample } \\
\text { size }\end{array}$ \\
\hline $\begin{array}{l}\text { L. perenne } \\
\quad \text { Cornish et al., }\end{array}$ & 0.1538 & 0.0252 & \\
$\begin{array}{l}\text { 1980) } \\
\text { L. multiflorum }\end{array}$ & & & \\
$\quad$ (Fearon et al., & 0.2414 & 0.0795 & \\
$\quad$ 1983) & 0.1852 & 0.0449 & 150 \\
$\begin{array}{l}\text { A. myosuroides } \\
\text { P. coerulescens }\end{array}$ & 0.1134 & 0.0312 & 207 \\
$\begin{array}{l}\text { F. pratensis } \\
\text { H. lanatus }\end{array}$ & 0.2381 & 0.0933 & 42 \\
S. cereale* & 0.2987 & 0.0563 & 132 \\
& 1) 0.0714 & 0.0668 & 28 \\
& 2) 0.1902 & & 30 \\
\hline
\end{tabular}

* Estimate 1) is from a single head from a full sib cross and 2) is an upper limit based on observing no recombinant in a collection of related full sib progenies where these plants were from bona fide crosses.

The estimate of the recombination frequency from $H$. lanatus is significantly greater than that for $L$. perenne, $P$. coerulescens and $S$. cereale. No other pair of these values is significantly different. These estimates are based upon the disturbance in the segregation ratio. Viability effects for GPI segregation were shown to be negligible since in all species undisturbed segregation ratios have been found in crosses of similar compatibility status. Thus the disturbed segregations observed are the result of linkage to the incompatibility factors and not due to viability effects. Whilst it is not possible to prove that it is the same self-incompatibility locus linked to Gpi, the close linkage values suggest that a unit has been conserved and that the same loci are involved in each species. 
Both Alopecurus myosuroides and Holcus lanatus show the same pattern of disturbed segregation and a similar linkage value. The observations strongly suggest that they also possess the two locus system of incompatibility.

\section{CONCLUSION}

These data should be of interest not only to workers on evolution, but also to plant breeders as it might be possible to extrapolate from the results of linkage studies in one grass species to possible linkage relationships in another. Such limited linkage data as are available certainly support this view (Miller, 1984; Brown, 1983).

A theoretical analysis of the effect, in terms of linkage disequilibrium (Leach et al., 1986), that a single locus gametophytic self-incompatibility system has on genes linked to it reveals that the enforced heterozygosity of the system does not shelter lethal mutations. Thus it is reasonable to assume that genes of economic importance closely linked to the incompatibility loci are neither protected nor less readily available for selection. However it was found that where an incompatibility system is operating selection intensities (for removing deleterious genes) of less than unity are more effective at lowering gene frequency than is complete selection.

Acknowledgements We acknowledge financial support from the Australian Research Grants Scheme. Mr Clive Chesson gave valuable technical advice.

\section{REFERENCES}

BROWN, A. H. D. 1983. In Isozymes in Plant Genetics and Breeding, Part B, Elsevier, pp. 57-77.

CORNISH, M., HAYWARD, M. D. AND LAWRENCE, M. J. 1980. Self-incompatibility in rye grass. III. The joint segregation of $S$ and PGI-2 in Lolium perenne L. Heredity, 44, 55-62.

DARlington, C. AND WYLIE, A. P. 1955. Chrosomosome Atlas of Flowering Plants, George Allen and Unwin, London.

FEARON, C. H., HAYWARD, M. D. AND LAWRENCE, M. J. 1983. Self-incompatibility in rye grass. V. Genetic control, linkage and seedset in diploid Lolium multiflorum Lam. Heredity, 50, 35-46.

HAYMAN, D. L. 1956. The genetical control of incompatibility in Phalaris coerulescens L. Aust. J. Biol. Sci., 9, 321-331.

LEACH, C. R. 1983. Are there more than two self-incompatibility loci in the grasses? Heredity, 52, 303-305.

LEACH, C. R., MAYO, O. AND MORRIS, M. 1986. Linkage disequilibrium and gametophytic self-incompatibility, (Accepted for publication Theoret. App. Genet.)

LUNDQVIST, A. 1954. Studies on self-sterility in rye Secale cereale L. Hereditas, 40, 278-294.

LUNDQVIST, A. 1955. Genetics of self-incompatibility in Festuca pratensis. Heredity, 41, 518-520.

LUNDQVIST, A. 1956. Self-incompatibility in Rye. I. Genetic control in the diploid. Hereditas, 42, 293-348.

LUNDQVIST, A. 1961. Self-incompatibility in Festuca pratensis Huds. Hereditas, 47, 542-562.

LUNDQVIST, A. 1969. The identification of the self-incompatibility alleles in a grass population. Hereditas, 61, 345-352.

MILLER, T. E. 1984. The homeologous relationships between the chromosomes of rye and wheat. Current Status. Can. J. Genet. Cytol, 26, 578-589.

MULLER, J. 1981. Fossil pollen records of extant angiosperms. Bot. Rev., 47, 1-142.

STE BBINS, G. L. 1971. Chromosomal Evolution in Higher Plants, Edward Arnold, London.

WEIMARK, A. 1968. Self-incompatibility in the Gramineae. Hereditas, 60, 157-166. 